\title{
RECUPERAÇÃO DA LIGNINA DA CASCA DE ARROZ DA VARIEDADE Oryza sativa PELO MÉTODO SODA
}

\author{
F.P. NORONHA ${ }^{1}$, N. O. CORAL ${ }^{1}$, R. B. RIBEIRO ${ }^{1}$, T. MARCHESINI ${ }^{1}$, e M. M. MORAIS ${ }^{2}$ \\ ${ }^{1}$ Universidade Federal do Pampa, Graduando(a) de Engenharia Química \\ ${ }^{2}$ Universidade Federal do Pampa, Curso de Engenharia Química \\ E-mail para contato: fpnoronh@gmail.com
}

\begin{abstract}
RESUMO - A lignina é um componente de tecidos vegetais responsável pela resistência mecânica da parede celular de plantas, podendo ser isolada e utilizada como matéria prima para uma série de produtos úteis tais como agentes, emulsificantes, antioxidantes, pesticidas, fertilizantes, polímeros, entre outros. Dentre os materiais lignocelulósicos, tem-se a casca de arroz (CA) Oryza sativa, variedade mais produzida na campanha gaúcha, desta forma este trabalho tem como objetivo estudar o processo de recuperação da lignina da casca de arroz pelo método Soda. A CA foi caracterizada quanto as suas características físicas obtendo os valores de $1.537 \mathrm{~kg} / \mathrm{m}^{3}$ e 0,74 para massa específica real e porosidade do leito respectivamente. Por meio da análise imediata foi possível determinar o teor de umidade de $10,06 \%$, o teor de materiais voláteis de $78,95 \%$, o teor de cinzas de $15,13 \%$, e o teor de carbono fixo em 4,48\%. Além disso obteve-se o teor de lignina Klason de $13,65 \%$, demonstrando que a matéria prima é rica em uma fonte de carbono, podendo ser utilizada como insumo na indústria química, aumentando o valor agregado da $\mathrm{CA}$. Em relação ao ensaio de tempo o maior rendimento obtido foi em 4 horas, e seu valor foi de 13,67\%, este resultado foi cerca de $43 \%$ maior que o obtido em $0,5 \mathrm{~h}$. Por fim, este trabalho sugere para um estudo futuro a análise das variáveis de processo que foram mantidas fixas, a fim de obter uma faixa de trabalho otimizada estatisticamente em relação ao rendimento do processo.
\end{abstract}

\section{INTRODUÇÃO}

\subsection{Casca de Arroz}

Segundo dados do IBGE (2016), a safra anual de arroz foi de 10,58 milhões de toneladas, sendo que $70 \%$ desse total foi produzido no estado do Rio Grande do Sul. O beneficiamento desta cultura origina grandes quantias de resíduos como a casca e palha do arroz. A casca do arroz equivale a cerca de $20 \%$ da massa do grão de arroz, é considerado um rejeito de baixo valor comercial sendo utilizado principalmente em compostagem e para fins energéticos (Kieling, 2009). Materiais lignocelulósicos como a casca do arroz Oryza sativa, variedade mais produzida na campanha gaúcha, são formados por celulose, hemicelulose e lignina, além de pequenas quantidades de cinzas (minerais) e extrativos (óleos e essências). (Pouey, 2006; Santos et al., 2012). 


\subsection{Lignina}

A lignina é um componente de tecidos vegetais responsável notadamente pela resistência mecânica da parede celular de plantas, é uma substância amorfa, de natureza aromática e muito complexa (Saliba et al., 2001), sendo responsável por cerca de $30 \%$ do carbono encontrado na natureza. A lignina é utilizada na maioria das vezes para fins energéticos por causa de sua estrutura molecular complexa (Pereira et al., 2007). No entanto, a lignina pode ser isolada e utilizada como matéria prima para uma série de produtos úteis, tais como agentes emulsificantes, antioxidantes, pesticidas, fertilizantes, polímeros, entre outros (Gargulak et al., 2000). Para realizar a extração da lignina presente na casca de arroz é necessário a utilização de pré-tratamentos que liberem os açúcares fermentescíveis e separe a lignina de sua matriz sólida. Dentre os métodos encontrados na literatura, os dois principais empregados industrialmente são os processos Kraft e Soda, sendo que ambos promovem a hidrólise da amostra com o auxílio de um licor de cozimento para recuperação da lignina. $\mathrm{O}$ processo Soda é mais brando e indicado para remoção da lignina mantendo sua maior integridade estrutural (Cardoso et al., 2009). As principais variáveis de processo do método Soda são a concentração do licor de cozimento (solução de $\mathrm{NaOH}$ ), o tempo de cozimento, a temperatura do processo, a pressão no reator, a intensidade da agitação e a relação licor de cozimento e matéria seca. Os principais parâmetros de avaliação do processo são o rendimento em lignina bruta e o teor de lignina residual.

Tendo em vista a importância do aumento do valor agregado da casca de arroz produzida na campanha gaúcha pela recuperação da lignina e da necessidade de se estudar os parâmetros de processo do método Soda, o presente trabalho teve por objetivo analisar a influência do tempo de recuperação da lignina presente na casca de arroz sobre o rendimento do processo.

\section{MATERIAIS E MÉTODOS}

\subsection{Matéria Prima}

A matéria prima utilizada foi casca de arroz (CA) da variedade Oriza sativa cedida por uma indústria beneficiadora de arroz da região de Bagé-RS. O trabalho foi desenvolvido nos Laboratórios de Engenharia Química da Universidade Federal do Pampa, Campus Bagé. A casca de arroz foi moída em moinho de facas da marca Marconi ${ }^{\circledR}$ tipo cróton, e a fração de partículas utilizada no trabalho foi a retida na peneira de mesh 60 .

\subsection{Procedimento Experimental}

A CA moída foi caracterizada fisicamente através da picnometria gasosa a hélio e ensaio de proveta para a determinação da massa específica real $\left(\rho_{\text {real }}\right)$ e aparente $\left(\rho_{a p}\right)$, respectivamente. O picnômetro gasoso foi da marca QUANTACHROMME INSTRUMENTS, com o auxílio de uma balança analítica marca SHIMADZU, modelo AUY220, precisão de $\pm 0,0001$ g. Com as informações da massa específica real e aparente, pode-se calculara porosidade do leito estático $(\varepsilon)$ segundo a Equação 1. 


$$
\varepsilon=1-\frac{\rho_{a p}}{\rho_{\text {real }}}
$$

A CA moída foi caracterizada quimicamente por ensaios de análise imediata e a quantificação da lignina Klason (LK). A análise imediata seguiu a norma NBR 8112; para a determinação do teor de umidade $(T U)$, utilizou-se estufa previamente aquecida a $105^{\circ} \mathrm{C}$, onde a amostra que foi mantida durante $24 \mathrm{~h}$. A amostra foi previamente seca e acondicionada em um forno mufla a $700{ }^{\circ} \mathrm{C}$ durante $4 \mathrm{~h}$ para a obtenção do teor de cinzas (TC). Para a determinação do teor de materiais voláteis $(T M V)$ aqueceu-se previamente o forno mufla a $900{ }^{\circ} \mathrm{C}$ e pesou-se $0,5 \mathrm{~g}$ de CA sobre a porta do forno mufla durante $3 \mathrm{~min}$; em seguida a amostra foi transferida para o interior da mufla, onde permaneceu durante $7 \mathrm{~min}$, mensurandose a massa residual da amostra. O teor de carbono fixo $(T C F)$ foi obtido analiticamente, sendo dependente dos teores de cinzas e materiais voláteis. A fim de determinar a quantidade de lignina Klason (TLK) através da norma TAPPI T 222 om-22 (2002c) (Morais, 2010), pesou-se cerca de 5,0 g de CA, a qual permaneceu sob agitação com ácido sulfúrico (72\%) durante 2,0 h; diluiu-se a solução com água destilada e submeteu-se a mesma ao refluxo por 4,0 h. Filtrou-se a amostra lavando-a até a neutralização do $\mathrm{pH}$; a fração sólida obtida foi levada à estufa $\left(105^{\circ} \mathrm{C}\right)$ durante $24 \mathrm{~h}$ e, posteriormente, foi levada ao forno mufla, aquecido previamente à $600^{\circ} \mathrm{C}$, durante $4,0 \mathrm{~h}$. O teor de lignina Klason foi obtido através da Equação 2 , sendo, $m_{r s, e}$ a massa de resíduo sólido volatilizado no forno mufla e $m_{a m}$ a massa da amostra.

$$
T L K=\left(\frac{m_{r s, e}}{m_{a m}}\right) \cdot 100
$$

A recuperação da lignina pelo processo Soda é apresentada esquematicamente no fluxograma da Figura 1.

Figura 1 - Esquema resumido da recuperação da lignina da casca de arroz pelo método Soda

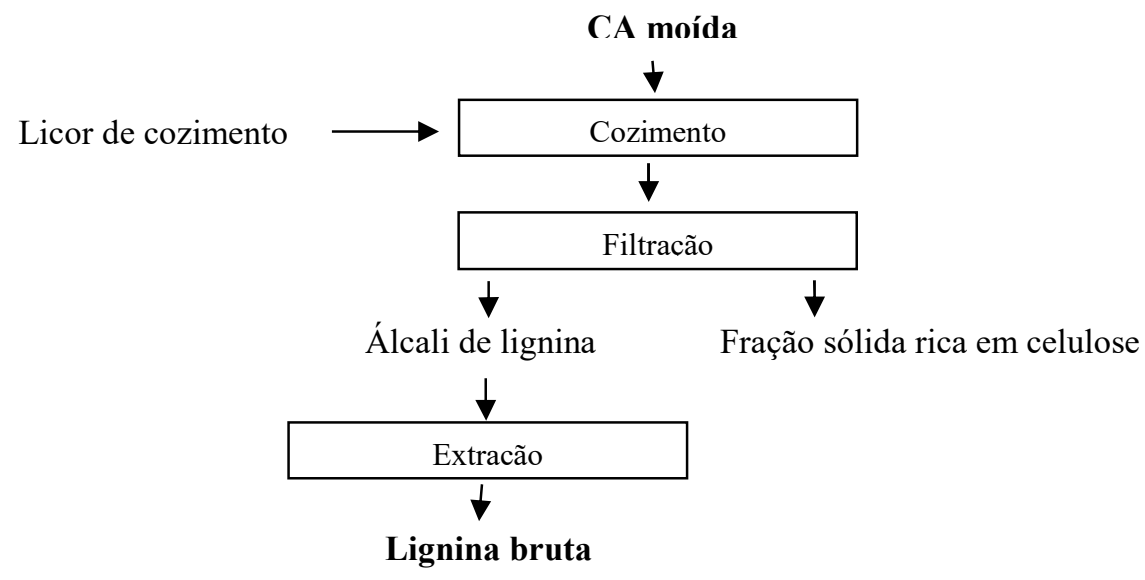

A CA moída (10 g) foi colocada em contato com o licor de cozimento (solução de $\mathrm{NaOH}$ 8\% em massa) a uma relação mássica licor:matéria seca de 6:1. A suspensão foi mantida a pressão atmosférica sob agitação semi-vigorosa em banho termostatizado a $50^{\circ} \mathrm{C}$. Foi analisado a influência do tempo de cozimento sobre o rendimento do processo em termos de lignina bruta; os tempos utilizados foram de 0,50 h, 2,25 h e 4,00 h. Após o cozimento, o 
extrato foi separado da fase sólida (resíduo de casca de arroz) através de filtração, obtendo-se o álcali de lignina. O filtrado foi diluído com água destilada e acidificado lentamente com ácido sulfúrico $70 \%$ para a precipitação da lignina bruta. A mistura foi centrifugada a 3.000 rpm durante $10 \mathrm{~min}$, sendo que a fase sólida contendo a lignina bruta foi seca em estufa $70^{\circ} \mathrm{C}$ por $24 \mathrm{~h}$. O rendimento do processo $(\eta)$ foi calculado pela Equação 3 sendo ms,lb a massa de lignina bruta obtida após a secagem em estufa.

$$
\eta=\left(\frac{m_{s, l b}}{m_{a m}}\right) .100
$$

\section{RESULTADOS E DISCUSSÃO}

A massa específica real da CA moída retida na peneira de mesh 60 foi de $1.537 \pm 2$ $\mathrm{kg} / \mathrm{m}^{3}$. Este valor difere bastante do encontrado por Souza (2011) para casca de arroz não moída, de $594 \mathrm{~kg} / \mathrm{m}^{3}$ utilizando ensaio de proveta; esta diferença pode ser justificada pela moagem das amostras utilizadas no presente trabalho, a qual aumentou a área superficial da casca de arroz, e pode ter promovido a abertura de poros fechados, também ao fato do método de proveta não ser tão preciso.

A porosidade do leito estático das partículas moídas foi de 0,74 , podendo-se considerar que as partículas formam um leito de alta porosidade, o que facilita os fenômenos de transferência de calor e de massa durante o processo de recuperação da lignina.

Através da análise imediata foi possível obter os valores dos teores de umidade, materiais voláteis, carbono fixo e cinzas da casca de arroz moída. Os resultados obtidos através da análise e os teores de lignina Klason estão apresentados na Tabela 2.

Tabela 1 - Análise imediata da CA e teor de lignina Klason

\begin{tabular}{|c|c|c|}
\hline Parâmetros & Autores (2017) & Horst (2013) \\
\hline \hline$T U(\%)$ & $10,06 \pm 0,06$ & 10,90 \\
\hline$T M V(\%)$ & $78,95 \pm 3,06^{*}$ & 81,60 \\
\hline$T C(\%)$ & $15,13 \pm 0,15^{*}$ & 10,30 \\
\hline$T C F(\%)$ & $4,48^{*}$ & 8,10 \\
\hline *base seca & $13,65 \pm 0,62 *$ & - \\
\hline
\end{tabular}

Com base na Tabela 1, observou-se que os parâmetros analisados apresentaram valores próximos aos encontrados na literatura para a caracterização química da casca de arroz. A variação no $T C F$ pode ter sido influenciada pela variedade do arroz; além disso, o teor de cinzas da CA encontrados no presente foi superior ao encontrado por Horst (2013), fornecendo como conseqüência menores valores de carbono fixo. Em relação ao teor de lignina Klason obteve-se um resultado dentro da faixa encontrada na literatura. Por exemplo, Diniz (2005) encontrou 19,2\% de lignina Klason em amostras de casca de arroz, enquanto que Pérez (2004) encontrou 14,3\%. A faixa relativamente ampla (13 a 30\%) se deve principalmente às diferenças nas variedades de arroz e também às diferenças nas condições de cultivo da biomassa. 
Na Tabela 2 são apresentados os resultados da análise da influência do tempo de cozimento $(t)$ sobre o rendimento do processo de recuperação da lignina bruta da CA de mesh 60 .

Tabela 2 -Rendimento de Lignina Bruta obtida pelo processo Soda a partir da CA moída

\begin{tabular}{|c|c|}
\hline$t(\mathrm{~h})$ & $\eta(\%)$ \\
\hline \hline 0,50 & $8,50 \pm 1,02$ \\
\hline 2,25 & $12,15 \pm 0,60$ \\
\hline 4,00 & $13,67 \pm 0,52$ \\
\hline
\end{tabular}

Com base nos dados apresentados na Tabela 2 foi possível observar que o rendimento em termos de lignina bruta no tempo de $2,25 \mathrm{~h}$ foi em média $43 \%$ maior do que quando o tempo de cozimento foi de $0,50 \mathrm{~h}$; já o rendimento obtido no tempo de 4,00 horas foi em média, 9\% maior do que no tempo de 2,25 h. Considerando que o teor de lignina Klason presente na CA moída foi de $13,65 \%$ em média, no tempo de processo de $4,0 \mathrm{~h}$ a lignina presente na amostra foi quase toda recuperada de sua matriz sólida. Este comportamento pode ser associado ao fato de que a amostra esteve em contato por um maior tempo ao meio alcalino, aumentou a hidrólise dos materiais lignocelulósicos, e como conseqüência, uma maior quantidade de lignina recuperada. No entanto, sabe-se que quanto maior o tempo de processo, maior é o consumo de energia; assim, os resultados sugerem que deve-se analisar a influência de outras variáveis de processo que neste trabalho foram mantidas fixas, como a temperatura, a concentração da solução de $\mathrm{NaOH}$ e a quantidade de licor adicionada à matéria prima, de modo que se obtenha uma alta eficiência de recuperação de lignina em um tempo de processo menor. A influência das variáveis de processo, bem como a magnitude destas influências pode ser analisada estatisticamente pela técnica do planejamento experimental, a qual poderá fornecer uma faixa de trabalho que combine um alto rendimento com um menor tempo.

\section{CONSIDERAÇÕES FINAIS}

A casca de arroz moída retida em peneira de mesh 60 apresentou uma massa específica real de $1.537 \mathrm{~kg} / \mathrm{m}^{3}$ e uma alta porosidade do leito estático $(0,74)$, o que reduz a resistência aos fenômenos de transferência de calor e de massa durante o processo de recuperação de lignina.

As amostras apresentaram teores de umidade, cinzas, materiais voláteis e carbono fixo dentro da faixa encontrada na literatura para casca de arroz. O teor médio de lignina Klason foi de $13,7 \%$, demonstrando que a casca de arroz, um material que gera o problema de deposição de grandes volumes em céu aberto, é rico em uma fonte de carbono, a lignina, a qual tem um grande potencial para uso como insumo na indústria química, aumentando o valor agregado da casca de arroz.

Os resultados sugeriram que deve-se analisar a influência das variáveis de processo que foram mantidas fixas no presente estudo, de modo a se obter uma faixa de trabalho otimizada estatisticamente com relação ao rendimento do processo, utilizando-se um menor tempo de cozimento. 


\section{REFERÊNCIAS}

ASSOCIAÇÃO BRASILEIRA DE NORMAS TÉCNICAS. NBR-8112: Carvão vegetal análise imediata. Outubro de 1986.

DINIZ, Juraci. Conversão térmica de casca de arroz à baixa temperatura: produção de bioóleo e resíduo sílico-carbonoso adsorvente. Santa Maria: PPGQ, 2005.

GARCIA, A.; TOLEDANO, A.; SERRANO, L.; EGUÉS, I.; GONZÁLES, M.; MAÍN, F.; LABIDI, J. Characterization of lignins obtained by selective precipitation. Separ. Purif. Tech., n. 68, pg 193-198, 2009.

HORST, D. J. Avaliação da produção energética a partir de ligninas contidas em biomassas. Dissertação (Mestrado em Engenharia de Produção), UTFPR, Ponta Grossa, 2013.

MORAIS, P. S. M.; ROSA, M. F.; MARCONCINI, J. M.; Procedimento para análise lignicelulósica. EMBRAPA. Campina Grande, 2010.

VARGAS, S.; N. Estudo preliminar da pirólise da casca de arroz. Trabalho de Conclusão de Curso (Engenharia Química), UNIPAMPA, Bagé, 2015

INSTITUTO BRASILEIRO DE GEOGRAFIA E ESTATÍSTICA. IBGE. Levantamento sistemático da produção agrícola. 2016. Disponível em: <https://sidra.ibge.gov.br>. Acesso em: mar. 2017.

KIELING, A. G. Influência da segregação no desempenho de cinzas de casca de arroz como pozolanas e material adsorvente. Dissertação (Mestrado em Engenharia Civil), UNISINOS, São Leopoldo, 2009.

POUEY, M. T. F. Beneficiamento da cinza da casca de arroz residual com vistas à produção de cimento e/ou composto pozolânico. Tese (Doutorado em Engenharia Civil), UFRGS, Porto Alegre, 2006.

CARDOSO, M.; OLIVEIRA, É. O.; PASSOS, M. L. Chemical composition and physical properties of black liquors and their effects on liquor recovery in Brazil pulp mills. Fuel, v. 88. p. 756-763, 2009.

SALIBA, E. O. S.; RODRIGUEZ, N. M.; MORAIS, S. A. L.; PILO-VELOSO, D. Ligninas: métodos de obtenção e caracterização química. Cienc. Rural, Santa Maria, v. 31, n. 5, p. 917-928, Oct. 2001.

SOUZA, Rafael Valim Xavier de. Caracterização e preparo da biomassa visando seu aproveitamento energético. 2011. 47 f. TCC (Graduação) - Curso de Engenharia de Energia, Centro de Engenharia, Modelagem e CiÊncias Sociais Aplicadas, Universidade Federal do Abc, Santo André, 2011. 